\title{
A FITA DE VÍDEO COMO RECURSO AUXILIAR EM EDUCAÇÃO FÍSICA
}

\author{
Nara Rejane Cruz de Oliveira*
}

\section{RESUMO}

Este trabalho pretende analisar a utilização de fitas de vídeo como recurso auxiliar nas aulas de Educação Física (EF) e na formação de professores, atuando como um coadjuvante no processo educativo e como veiculador de valores numa perspectiva crítica de EF.

PALAVRAS-CHAVE: Fitas de vídeo, Educação Física, esportes.

\section{INTRODUÇÃO}

Cada vez mais, fitas de vídeo e outros recursos audiovisuais têm sido utilizados nas aulas de Educação Física, seja nas escolas ou nas disciplinas dos cursos de formação de professores. Entende-se que este recurso é "relevante para processos educacionais, em particular para a Educação Física, na medida em que o vídeo é uma possível forma de usufruto da cultura corporal"'(Ferreira, 1996, p. 39).

Neste sentido, busca-se aqui analisar este recurso. Para tanto, inicialmente será feita uma relação entre mídia e EF/Esportes , apontando fatores positivos e negativos que influenciam esta relação, a saber: reprodução de valores hegemônicos em EF/Esportes e possibilidade de democratização dos meios de comunicação para veiculação de informações acerca de EF/Esportes.

Partindo destes pressupostos, serão analisadas duas fitas de vídeo sobre basquete: "Aprenda a jogar basquete", produzida pela Vídeo Ban (TV Bandeirantes), e a fita de uma aula de basquete produzida por um

\footnotetext{
* Professora do Curso de Educação Física da UFG/CAC.
}

72 Oliveira, N. R. C. - A fita de vídeo como recurso auxiliar em ... 
coletivo de alunos em um curso de especialização em Educação Física Escolar. ${ }^{1} \mathrm{O}$ objetivo desta análise comparativa será o de apontar quais os valores veiculados por estas fitas, bem como suas possíveis contribuições no âmbito da EF escolar e na formação profissional.

\section{MÍDIA E EDUCAÇÃO FÍSICA/ESPORTES}

Entende-se aqui por mídia o "veículo que leva determinadas informações/conhecimentos ao público em geral ou determinado público especial, trabalhando com certos tipos de estratégias e técnicas criativas", (Comissão Sistematizadora, 1996). Ou ainda,

o conjunto de meios de comunicação para alcançar as massas[...]. Não podemos deixar de mencionar que ela [mídia], é uma organização intencionada em estruturar e reforçar a consciência do sujeito social, via veiculação de informação, de acordo com os interesses e valores da classe dominante. Possui um caráter subjetivo de controle ideológico e cultural (Pirolo e Terra, 1996).

É pois, segundo Souza (1996), “um dos aspectos ideológicos da classe dominante. Utiliza-se de símbolos, mitos, esportes e imaginário coletivamente construídos para exercer seu papel".

Reproduzindo os valores da classe dominante e hegemônica, ou seja, seus modismos, interesses, padrão de vida etc, podemos dizer que a mídia age sobre as classes populares ou subalternas, as quais terminam por adotar estes valores como sendo seus.

Para Carnoy (1988, p. 95), o conceito gramsciano de hegemonia tem dois significados principais: o primeiro é um processo na sociedade civil pelo qual uma parte da classe dominante exerce o controle, através de sua liderança moral e intelectual, sobre outras frações aliadas da classe dominante. A fração dirigente detém o poder e a capacidade para articular os interesses de outras frações. Ela não impõe sua própria ideologia ao grupo aliado, mas antes "representa um processo politicamente transformativo e pedagógico, pelo qual a classe (fração) dominante articula um princípio hegemônico, que combina elementos comuns, extraídos das visões de mundo e dos interesses dos grupos aliados" (Giroux, 1981). O segundo é a relação entre as classes dominantes e as dominadas. A hegemonia compreende as tentativas bem-sucedidas da classe dominante em usar sua liderança política, moral e intelectual para impor 
sua visão de mundo como inteiramente abrangente e universal e para moldar os interesses e necessidades dos grupos subordinados.

Neste contexto, não é mais possível discutir o esporte sem incluir nesta discussão os meios de comunicação/mídia. Neste sentido, verificamos que há muito o esporte deixou de ser apenas uma manifestação que se expressa pelo movimento humano, pelo lúdico e é hoje uma mercadoria idêntica a qualquer outra.

Desta forma, a EF e, especialmente, o esporte têm sido historicamente reproduzidos nos meios de comunicação de massa, afirmando valores da sociedade capitalista, como a competitividade exacerbada, o individualismo etc, mostrando o esporte como um fim em si mesmo e "sinônimo de EF". 2

Isso se dá porque o esporte tem sido um dos fenômenos mais lucrativos da atualidade e tem atraído milhões de pessoas no mundo inteiro.

Ora, a mídia, como negócio lucrativo, promove e divulga grandes eventos esportivos nacionais e internacionais. Mas a ênfase dada a tais eventos, "no intuito de reforçar valores dominantes, impele o homem tanto a desejos consumistas quanto à valorização da corporeidade, como expressividade de competência"3 (Pirolo, 1996, p. 240).

Neste sentido, o esporte acaba adquirindo o estatuto de mercadoria. Segundo Silva (1996, p. 247), "a mídia exerce um efeito poderoso na difusão do modelo corporal 'de consumo', fazendo com que a busca por esse modelo dominante, homogêneo no Ocidente, torne-se uma necessidade quase inquestionável para os indivíduos".

Neste contexto, o esporte tem-se tornado em "produto cultural altamente valorizado em todo mundo, pelo menos no sentido econômico" (Kunz, 1994, p. 22). O que contribui também para que o esporte se torne cada vez mais padronizado nas aulas de EF, seguindo o modelo hegemônico, de rendimento, geralmente importado, o que contribui para a falta de atividades criativas, tanto do professor quanto do aluno.

Sobre a Educação Física, deve-se deixar claro que aqui ela é entendida como profissão e disciplina curricular, que faz parte de um projeto histórico de sociedade, sendo sua prática socialmente produzida e culturalmente desenvolvida - portanto, uma prática política. Tendo como eixo de ação a cultura corporal e estando ligada a um projeto histórico de sociedade oposto ao capitalista, deve ser uma prática cons- 
ciente, ligada a uma pedagogia crítica e problematizadora, no intuito de contribuir para a formação de indivíduos críticos que produzem conhecimento e não o contrário.

Desta forma, tem-se claro que esta mídia, por um lado, manipula e inculca valores ideológicos e, por outro, é um potente veículo de informação. Pode e deveria ser utilizada no âmbito da democratização dos meios de comunicação, para possibilitar a veiculação de informações acerca da EF/Esportes, que hoje são fragmentadas. Portanto, falar em democratizar os meios de comunicação seria pensar em uma forma, através da mídia, de contribuir até mesmo para o desenvolvimento das Ciências do Esporte ou uma Metodologia de EF que privilegie a cultura corporal e uma prática consciente/crítica. Segundo Muller (1996, p. 217), "no mundo dos esportes quase inexiste um caráter crítico-esclarecedor". A EF, enquanto parte de um sistema educacional, pode e deve promover uma leitura crítica da imagem do esporte, que se constitui em conteúdo de suas aulas. "Ler imagens criticamente implica aprender como apreciar, decodificar e interpretar imagens, analisando tanto a forma como elas são construídas em nossas vidas, quanto o conteúdo que elas comunicam em situações concretas" (Kellner, 1995, p. 109).

Como parte da mídia, o setor de vídeos também tem sua contribuição (positiva ou negativa) na EF/Esportes. O esporte enquanto "produto cultural" também está à disposição sob a forma de vídeos sejam de futebol (Copa do Mundo etc), ginástica, vôlei, natação, basquete etc, que podem ser locados ou comprados nas lojas.

\section{A FITA DE VÍDEO COMO RECURSO: UMA ANÁLISE.}

A fita de vídeo é aqui entendida como um recurso alternativo, que contribui tanto nas aulas de EF escolar quanto na formação profissional da área.

Partindo deste pressuposto, foram analisadas duas fitas de vídeo, cujo conteúdo é o basquete. Estas análise se faz necessária, devido ao fato de que deve-se ter claro quais valores, mensagens e conteúdos veiculados pelas fitas que se pretende utilizar e de que forma, em que contexto elas podem e/ou devem ser utilizadas.

O basquete foi o esporte escolhido por ser um conteúdo da cultura corporal que está presente no cotidiano da EF escolar e também por se constituir em disciplina nos cursos de formação profissional em EF. 
A primeira fita de vídeo intitula-se "Aprenda a jogar basquete" e foi lançada pela Vídeo Ban, sendo divulgada pela TV Bandeirantes.

Em primeiro lugar, deve-se considerar o fato de que esta fita foi produzida como parte de um empreendimento empresarial, com fins comerciais lucrativos. Em consequiência disto, segundo Ferreira (1994), "há possibilidade de distorções e/ou falsificações nas mensagens veiculadas por este tipo de fita, bem como o fato de que a mesma reflete e reforça a hegemonia do esporte na cultura corporal".

A propaganda desta fita na TV Bandeirantes mostra a possibilidade de o telespectador/consumidor aprender a jogar basquete praticando os exercícios e fundamentos advindos da NBA, a liga de basquete norteamericana de alto nível. Além disso, em um procedimento ideológico, oculta deste mesmo consumidor o fato de que ele "corre o risco de ver frustradas as suas expectativas de aprender a jogar basquete. Porque, afinal, muitos dos melhores atletas olímpicos nunca chegam ao nível profissional da NBA" (Ferreira, 1994, p. 45), ou seja, oculta do consumidor que nenhuma pessoa se transforma em "astro" do basquete pelo simples fato de comprar e praticar (leia-se tentar praticar) o conteúdo de tal fita.

O conteúdo da fita, além de mostrar os fundamentos/técnicas do basquete norte-americano, afirma que com garra e esforço próprio (individualismo) é possível a qualquer pessoa se tornar uma grande jogadora, uma vencedora, assim como os craques da NBA. Aqui a ideologia liberal se faz presente, pois a fita ressalta valores como o individualismo (devido ao fato de que toda iniciativa parte do telespectador/consumidor) e a meritocracia, "que advoga a superação de dificuldades/obstáculos, no caso aprender/aperfeiçoar-se num dos esportes em tela, escamoteando as condições materiais de vida numa sociedade capitalista, que privilegiam uma classe e não outra" (Ferreira, 1994, p. 45). Além disto, o modelo norte-americano do esporte sugere maior credibilidade ao produto, pelo fato de os Estados Unidos serem uma potência olímpica no basquete. Outro fato de relevância nesta fita é o caso de que a mesma é comercializada no intuito de ajudar o consumidor na aprendizagem do esporte. No entanto, ela contém o modelo do basquete de alto rendimento, que até alguns atletas teriam dificuldades em praticar. Então pergunta-se: se o objetivo da fita é a aprendizagem do esporte, por que não começar de um nível acessível ao desempenho esportivo mais elementar? 
Pode-se observar também que o conteúdo da fita se prende somente aos gestos automatizados, à repetição ( e consequiente fragmentação dos movimentos) e o aspecto norteador é a aptidão física. Enfim, aprender jogar basquete significa assimilar da melhor maneira os fundamentos, técnicas e regras do esporte.

No caso do esporte escolar em uma aula de EF, conteúdos apresentados desta forma contribuem para a importação de modelos esportivos de alto rendimento. A adoção destes modelos de esportes importados traz como consequiência a falta de criatividade nas aulas, bem como o selecionamento de alunos em detrimento da frustração de outros. Kunz (1991), apud Ferreira (1996), afirma que:

As consequiências disto são evidentes na observação de uma aula de Educação Física onde, na tentativa de copiar de forma irrefletida o esporte competitivo e normativo do mundo dos esportes organizados e de competição, introduz-se no interior da escola, ou da Educação Física Escolar, os 'princípios básicos' deste esporte, ou seja, 'princípios da sobrepujança' e das 'comparações objetivas' e suas conseqüências imediatas: as tendências do 'selecionamento', da 'especialização' e da 'instrumentalização'.

Por outro lado, esta fita de vídeo pode também ser utilizada em aulas de EF, no sentido de promover uma problematização, uma crítica a este modelo de esporte e instigar os alunos ao desenvolvimento de um modelo esportivo que atenda às necessidades da realidade em que vivem. Entende-se também que a EF numa perspectiva crítica não nega o conteúdo sistematizado, portanto esta fita aliada a uma discussão/debate a respeito do esporte pode ser apresentada aos alunos com significativas contribuições.

A segunda fita foi produzida pelo coletivo de alunos do curso de Especialização em EF escolar, durante algumas aulas da disciplina Fundamentos e Metodologia da EF escolar. Esta aula foi programada devido à necessidade sentida pelos alunos do referido curso, em relacionar a teoria de uma EF crítico-superadora à sua prática no cotidiano escolar. Também houve uma necessidade de registrar tais aulas, visto que foram contextualizadas à realidade atual da EF no âmbito escolar.

A produção desta fita contou com os grupos de trabalho organizados, que apresentaram, cada um, uma aula de basquete, na concepção 
crítico-superadora. Vale ressaltar que foi uma produção amadora, que contou com a boa vontade dos participantes, tanto os que estavam em quadra quanto os que se revezavam nas filmagens.

Sendo uma aula na concepção crítico-superadora, o basquete aparece como elemento da cultura corporal. Todo o conhecimento a respeito deste esporte foi historicizado, com base na dinâmica relatada. Foram formados cinco grupos com mais ou menos seis componentes cada. $\mathrm{O}$ professor da disciplina coordenava as atividades, dando a cada grupo a tarefa de contextualizar o basquete em determinada época de sua história e de apresentar um jogo de acordo com esta, em que os demais participariam como alunos. Assim, foram apresentadas formas de jogos que retratavam o basquete atual, na época da Guerra Fria (conflitos políticos), o basquete na época de seu surgimento etc. Desta forma, os alunos puderam vivenciar e perceber que este esporte não surgiu como o conhecemos hoje, mas foi uma atividade do homem historicamente produzida e culturalmente desenvolvida, de acordo com as necessidades de cada época. Após cada apresentação, aconteciam discussões no coletivo, que contribuíam para uma melhor socialização do conhecimento e mesmo para críticas.

Em outra aula, em parte desta mesma fita, também foram praticados alguns fundamentos do basquete sob forma de jogos, em que, no final, sempre havia espaço para as discussões em grupo. Ou seja, o conteúdo sistematizado não foi negado aos alunos que o aprenderam no coletivo, vivenciando o esporte em sua realidade atual e o apreendendo na totalidade.

Entende-se que esta fita poderá proporcionar ao aluno um real aprendizado coletivo, negando os valores hegemônicos e os modelos esportivos prontos, de alto rendimento e veiculando outros, como o coletivismo, por exemplo.

Este vídeo poderá também auxiliar na formação de professores numa perspectiva crítica de EF, a partir do momento em que procura dar sentido/significado à atividade/esporte, com relevância para o processo educativo.

Podem-se também utilizar estas duas fitas analisadas, no intuito de realizar um debate entre os alunos a partir da apresentação de ambas, para que os mesmos possam fazer suas próprias comparações e avalia-

Oliveira, N. R. C. - A fita de vídeo como recurso auxiliar em ... 
ções, bem como criticar e apontar possíveis soluções para uma prática esportiva escolar que atenda aos interesses de uma maioria.

\section{CONCLUSÃO}

Este ensaio teve como preocupação não só apontar a fita de vídeo como recurso alternativo auxiliar na EF, mas também de entender (ou pelo menos tentar) que a $\mathrm{EF}$, que tem como um de seus conteúdos o esporte, vem sido deturpada em seu sentido. Ou seja, uma disciplina curricular, que entende-se ter como objetivo auxiliar na formação escolar do indivíduo, tem sido alvo da mídia/meios de comunicação que dão ao esporte (seu conteúdo) um sentido positivista. Portanto, é viável que se tente, pelo menos, buscar alternativas para que este problema se solucione.

Entende-se que somente utilizar as fitas de vídeo, dando-lhes um sentido crítico, valores ou produzir fitas amadoras (ação a médio prazo) que veiculam valores socialistas, não se constitui na resolução do problema, que aliás merece muita reflexão a respeito. Deve-se também propor uma perspectiva de ação a longo prazo. Neste ponto, recorre-se a Ferreira (1996, p. 52) que diz:

Do ponto de vista funcionalista poder-se-iam propor reformas no fenômeno isoladamente e ponto final, sem questionar seus fundamentos (sua economia política). Dialeticamente, no entanto, devese ir às raízes do fenômeno. Criticá-lo é criticá-las: transformá-lo (o fenômeno) é transformá-las (suas raízes). Devemos, portanto, atuar no curso das lutas políticas colocadas em nosso cotidiano, partindo não de nossos desejos que projetam o que gostaríamos que fosse realidade, e sim desta como ela é e está neste dado momento.

Quanto à contribuição das fitas de vídeo amadoras, que, como mencionado, é de grande relevância para a área de EF/esportes. Ainda segundo Ferreira (1996, p. 52):

Assim, o vídeo enquanto recurso audiovisual à disposição da divulgação e fomento da cultura corporal, poderia colocar-se nas seguintes perspectivas (entre outras): 
a) veicular outras concepções (formas) de esporte voltadas para Educação e Educação para o lazer.

b) maior abrangência de elementos da cultura corporal, não limitando-se ao esporte.

c) possibilidade de usufruto público de tais fitas, não submetidas a leis de mercado.

d) baixo custo de produção, pois não visariam ao lucro e à concorrência no mercado.

e) ensinar o esporte e/ou outras atividades corporais de forma adequada às necessidades e realidades locais.

f) respeito à cultura de movimento tradicional naquela localidade ou região.

Para concluir, deve-se deixar claro que a mídia não é somente uma influência negativa, mas também pode trazer contribuições.

Desta forma, as fitas e os meios de comunicação em geral podem propiciar contribuições positivas para a vida do educando, dependendo da forma como o aluno apreende. Segundo Kellner (1995, p. 109):

A educação certamente deveria prestar atenção a essa nova cultura, tentando desenvolver uma pedagogia crítica que estivesse preocupada com a leitura de imagens. Ler imagens criticamente implica aprender como apreciar, decodificar e interpretar imagens, analisando tanto a forma como elas são construídas e operam em nossas vidas, quanto o conteúdo que elas comunicam em situações concretas.

Deve-se entender também que possíveis soluções para o 'caos' capitalista em que estamos não acontecem da noite para o dia. São ações a longo prazo, que dependem também de nossa real vontade/necessidade de oposição ao individualismo/capitalismo para caminhar rumo a uma sociedade socialista e igualitária. Para tanto, devemos nos arriscar a mudar, não só nossa prática escolar, mas também nossa prática de vida.

\section{ABSTRACT}

This paper aims to analyse the use of videotapes as an auxiliary resource in physical education classes and in teacher's formation. Videotapes could act as a helper in the educational process as well as in the act of transmitting values in a critical perspective of physical education.

KEYWORDS: Videotapes, physical education, sports.

80 Oliveira, N. R. C. - A fita de vídeo como recurso auxiliar em ... 


\section{NOTAS}

1. Curso realizado na Esefego durante o ano de 1997. A fita foi produzida em uma aula da disciplina Fundamentos e Metodologia da Educação Física Escolar.

2. A expressão "sinônimo de EF" é aqui utilizada para designar uma EF desportivizada e estigmatizada em esportes de rendimento.

3. A expressão "corpo como expressividade de competência" diz respeito à busca da competência como forma de alcançar um reconhecimento social, através do esporte de rendimento. É o caso de atletas famosos, por exemplo.

\section{REFERÊNCIAS BIBLIOGRÁFICAS}

CARNOY, Martin. Estado e teoria política. 2. ed. Campinas, SP: Papirus, 1988.

COMISSÃO SISTEMATIZADORA. V SMEE "Esporte e mídia". In: Caderno de Debates EXNEEF. v. 4, set. 1996.

FERREIRA, Marcelo Guina. Educação Física Escolar, Esportes e Recurso Audiovisual: o Videoteipe. In: CARVALHO, Sérgio (Org.) Comunicação, movimento e mídia na Educação Física. Santa Maria, RS: Palloti, v. 3, 1996.

KELLNER, Douglas. Lendo imagens criticamente: em direção a uma pedagogia pós-moderna. In: SILVA, Tomaz Tadeu da (Org). Alienígenas em sala de aula: uma introdução aos estudos culturais em educação. Petrópolis: Vozes, 1995.

KUNZ, Elenor. Transformação didático-pedagógica do esporte. Ijuí: Unijuí, 1994.

MULLER, Uwe. Esporte e mídia: um pequeno esboço. In: Revista Brasileira de Ciências do esporte. v.17, n. 3, maio 1996.

PIROLO, Alda Lúcia. O processo de comunicação e informação: sua influência no movimento do homem em movimento no mundo. In: Revista Brasileira de Ciências do Esporte. v. 17 n. 3, maio 1996.

PIROLO, Alda Lúcia, TERRA, Dináh V. Esporte e mídia. In: Caderno de Debates EXNEEF. v. 4, set. 1996.

SILVA, Ana Márcia. Das práticas corporais ou porque o Narciso se exercita. In: Revista Brasileira de Ciências do Esporte. v. 17 n. 3, maio 1996.

SOUZA, Edilson Fernandes. Esporte e mídia. In: Caderno de Debates EXNEEF. v. 4, set. 1996. 